\title{
Experimental Study of Radial Lip Seals with Different Sleeve Coatings
}

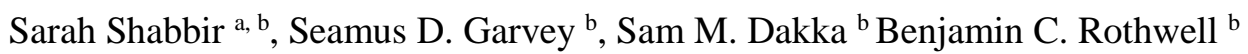 \\ ${ }^{a}$ Institute of Aerospace Technology, Aerospace Technology Centre, University of Nottingham, Nottingham, United Kingdom \\ ${ }^{\mathrm{b}}$ Gas Turbine and Transmission Research Centre, Department of Mechanical, Materials and Manufacturing Engineering, University of \\ Nottingham, Nottingham, United Kingdom
}

\begin{abstract}
Radial Lip Seals with pre-loaded garter springs of $8.5 \mathrm{oz}, 12.5 \mathrm{oz}$ and $14 \mathrm{oz}$ are tested with 4 different sleeves to investigate various seal-sleeve combinations. To find optimum sleeve coating and seal combinations, leakage and performance is investigated on an experimental test bench. This paper analyses a) Performance of various seal-shaft combinations, $b$ ) performance of varying seal pre-loaded garter springs, c) exploring the importance of a coating by comparing a stainless steel shaft to the 3 other coatings and d) integrity of sleeves after testing. Results indicate that the tungsten carbide coated sleeve outperforms the chrome oxide, hard chrome and stainless steel sleeves in terms of leakage. Chrome oxide is second in performance, third is hard chrome and the stainless steel sleeve leaked the most. Further, the tungsten carbide, chrome oxide and hard chrome sleeves are all surface finished to the desirable roughness, $R a=0.2-0.4 \mu \mathrm{m}$ while the stainless steel sleeve is not. This shows that surface coatings are significant; Vickers hardness and surface roughness of a sleeve are important factors to consider in the design process, necessary for efficient sealing. The $14 \mathrm{oz}$ spring, in all cases, exhibits higher leakage than the $12.5 \mathrm{oz}$ and $8.5 \mathrm{oz}$ springs. This indicates that the higher load spring results in higher wear and therefore, higher leakage. Optimum performance and lowest leakage is seen in the $12.5 \mathrm{oz}$ spring seal.
\end{abstract}

\section{Introduction}

Radial lip seals have a 1-10 $\mu \mathrm{m}$ lubricating film of liquid that separates the lip from the shaft. This film is necessary to prevent damage to the lip due to mechanical stresses and heat generation at the lip-shaft interface [1]. As shown in fig. 1, the seal consists of (1) a lip which is for sealing with the rotating shaft, (2) an outer static seal, (3) a metal reinforcement which supports the lip and (4) a garter spring which provides the pre-load on the shaft surface for sealing.

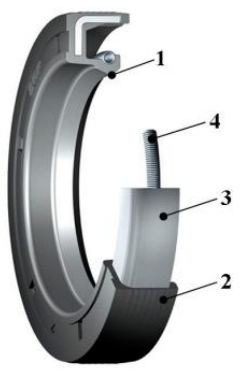

Figure 1: Radial lip seal schematic [2]

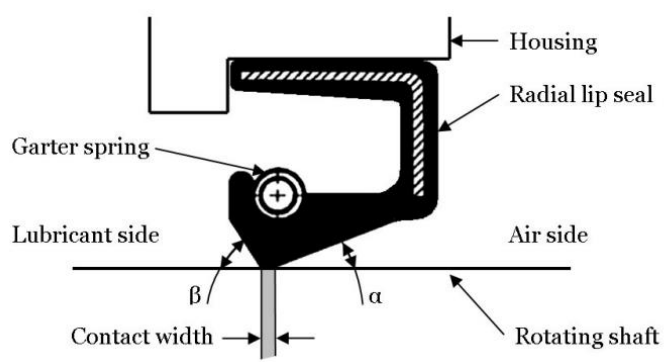

Figure 2: Radial lip seal shaft-seal interface [3]

Fig. 2 displays the seal mounted on the shaft with an interference fit. The garter spring presses down on the lip with some pressure. The pressure distribution under the lip, where it makes contact with the shaft is an important part of the sealing mechanism. The surface interaction between the shaft and the seal lip is critical, as this is where the sealing phenomenon actually takes place. Hence, the surface characteristics of the shaft and seal at microscopic levels are critical as well.

To minimize leakage, the combination of the seal surface and shaft surface must work well together. Since zero-leakage seals do not exist, the acceptable level of leakage through a seal is based on the industry and application. In the aerospace industry, the specifications of the shaft are clear in terms of surface roughness guidelines. A certain roughness is necessary for the seal to perform effectively [4].

Research continues to be carried out around how seals work and preventing undesired leakage to fill gaps in understanding sealing mechanisms [1][2][5]. However, there still is several research present on experimental works investigating the sealing mechanism of radial lip seals. In 1957, Jagger's [6] work proved the existence of a lubricant film between the lip and the shaft. Usually, anything $10 \mu \mathrm{m}$ and less is known as a film. He noticed that the seal lubricated with oil exhibited much lower friction than seals that experienced dry friction. Further experimentation confirmed that the lubricant film remains present when the radial load of the lip on the shaft is increased. Additionally, the existence of this lubricant film in the annuli between the seal and shaft has subsequently been confirmed by many other researchers as well [7], [8]. 
The lip temperature is a crucial parameter that contributes to seal life as high temperatures enhanced by friction, misalignment and high rotational speeds will result in heat development. All this will limit the life span of the seal and is important to take into consideration [9].

All of these factors are effected by the seal-running surface i.e. the sleeve. It is important to note that a high quality, perfectly designed and superior seal will not perform well without the correct running surface. This includes the optimum sleeve surface finish and coating. If these factors are not included in the selection process, the PTFE radial lip seal will not seal efficiently for long periods [10]. In the work presented, the following is investigated:

a. Performance of various seal-shaft combinations by testing with 4 different sleeve coatings: tungsten carbide, chrome oxide, hard chrome and stainless steel.

b. Performance of varying pre-loaded garter springs on the lip seals: $8.5 \mathrm{oz}, 12.5 \mathrm{oz}$ and $14 \mathrm{oz}$.

c. Exploring the importance of a coating by comparing a stainless steel shaft to the 3 other coatings.

d. Integrity of sleeves after testing.

\section{Design of Test Rig}

Fig. 3 below is a schematic of the test rig for this experiment. Section 1, 2 and 3 are explained below.

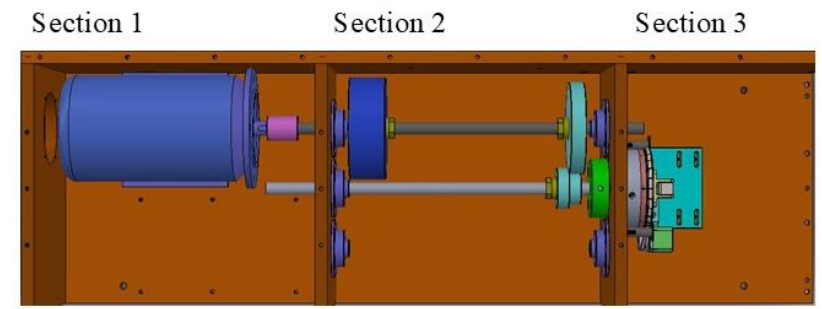

Figure 3: Test Rig Layout

Section 1 consists of the prime mover, the motor (specifications in table 1).

Table 1: Motor Specifications

\begin{tabular}{|l|l|}
\hline Parameter & \multicolumn{1}{|c|}{ Value } \\
\hline Rated Power & $P_{r}=2.2 \mathrm{~kW}$ \\
\hline Poles Pair & $p=2$ \\
\hline Frequency & $f=50 \mathrm{~Hz}$ \\
\hline De-rated max speed & $\omega_{\max }=3000 \mathrm{rpm}$ \\
\hline
\end{tabular}

Section 2 consists of the gears transmission, input shaft and output shaft. The gears have a 1:3 ratio and there is a bearing and seal (in green) in this section to provide stability to the rig and reduce vibrations.

Section 3 is the redesigned test bench (Fig. 4a and 4b). To test different seals, the schematic consists of a stationary seal attached to the main housing. The seal is mounted on a different sleeve in each test. The sleeve is fitted to the shaft using a hydraulic coupling, clamping outward onto the sleeve and inward onto the shaft. This ensures that the sleeve will rotate with the shaft, resulting in a dynamic sealing environment. Everything is enclosed in a Perspex chamber which will be filled up with turbine engine oil, Aero shell 555, to simulate a helicopter gearbox or a bearing chamber.

There is a periscope set up with a mirror mount retainer to facilitate magnified observation of the seal-shaft interface. The mirror mount retainer is fitted onto a mount with a toothed belt. The belt is connected to a stepper motor and will rotate the mirror mount retainer slowly 360 degrees, resulting in a magnified view of the entire circumference of the seal-shaft interface. The stepper motor is a 2 phase, 4 wire cable, and bipolar motor. Its step angle is 1.8 degrees and it has a holding torque of 22 $\mathrm{Nm}$. This particular set up is to observe the seal-shaft interface across the entire circumference with a high speed camera while the test is being conducted. This facilitates a better view as the entire rig is covered during operation. Further, the pattern and timing of leakage can be better observed in this manner. 

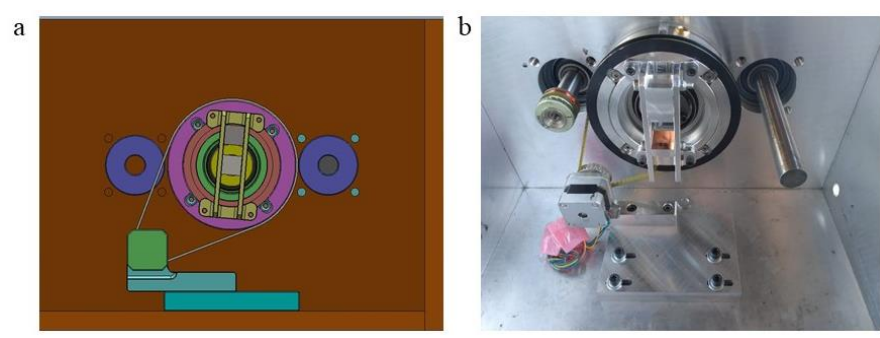

Figure 4: (a) Schematic of section 3 of the test bench. (b) Image of section 3 on the test bench.

In this application, seals are placed in the input and output housing of the gearbox. In terms of rotational speed this varies according to the location of the seal in the gearbox. For example in some cases, the engine input speed is approximately 6,250 $\mathrm{rpm}$ on a $\emptyset 66 \mathrm{~mm}$ shaft $(21.6 \mathrm{~m} \mathrm{~s}-1$ seal surface speed) and the main rotor output is approximately $330 \mathrm{rpm}$ on a $\varnothing 275 \mathrm{~mm}$ shaft (seal surface speed $4.8 \mathrm{~m} \mathrm{~s}-1$ ). For the purpose of this study, seal surface speeds between $5-20 \mathrm{~m} / \mathrm{s}$ are considered with $360 \mathrm{rpm}-6000 \mathrm{rpm}$ on the output shaft.

The highest frequency of the motor is $50 \mathrm{~Hz}$ on the input shaft, which is $3000 \mathrm{RPM}$. The gears connecting the input and main shaft have a ratio of 1:3. Hence, the highest speed on the main shaft is 9000 RPM. Further, the motor is a 2 pole motor (table 1). These calculations are done using equations 1,2 and 3 and are referred to in table 4.

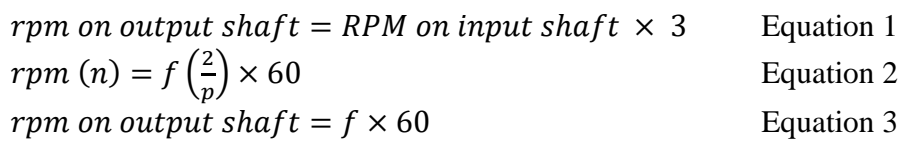

Hence, we will only use the motor at a maximum frequency of $\sim 33.3 \mathrm{~Hz}$, yielding $\sim 2000 \mathrm{rpm}$ on the input shaft of the test rig and $\sim 6000 \mathrm{rpm}$ on the main shaft of the test rig.

\section{Materials}

Seals: Radial lip PTFE oil seals with three different springs $8.5 \mathrm{oz}, 12.5 \mathrm{oz}$ and $14 \mathrm{oz}$ are used in this experiment. The stationary seal is mounted on the sleeve with an interference fit, connected to the main housing and does not rotate.

Sleeves: Sleeves are used for testing as it is economically and logistically more feasible to surface treat small sleeves rather than entire shafts. The sleeves will be mounted on the shaft and rotate with it. The coatings on the sleeves along with the surface profile and manufacturing methodology determines the performance of the seal. The different types of coatings tested in this work are:

a. Hard chrome: Commonly used in aerospace applications. However, industry is moving away from this as it polishes in overtime with high fatigue and wear [11].

b. Chrome oxide: A common shaft coating used in many industries, especially aerospace.

c. Tungsten carbide: Also known as hardide coatings and are increasingly popular as they do not polish in over-time, maintain their surface roughness. They also offer improved wear and fatigue over other coatings.

d. Stainless steel: This represents a plain stainless steel shaft.

All sleeve coatings are tested to study their performance with the PTFE lip seal with 3 loaded springs.

Lubricant: Aeroshell 555 is the lubricant of choice for this study as it is a standard gearbox turbine engine oil that is compatible with several helicopters [12].

\section{Research Methods}

Leakage of oil through the seal is measured to find the leakage rate for each seal and sleeve combination. A drip tray is set up to collect oil that leaks and is measured using a syringe. The standard acceptable limit of leakage in aerospace applications is known to be $1 \mathrm{ml} /$ hour.

\subsection{Hardness testing}

Prior to the experiment, all sleeves are tested for Vickers hardness. This test is conducted with a pyramid hardness-testing machine. Most specimens come with a range of specified hardness values and this range can be large. The purpose of this test 
is to find out the exact hardness value of the specimen and to ensure it falls within the range. Table 2 shows the Vickers hardness of all 4 sleeves used in this test.

Table 2: Sleeve Vickers Hardness (units: VH)

\begin{tabular}{|l|l|}
\hline Coating & Vickers Hardness \\
\hline Hard chrome & 450 \\
\hline Chrome Oxide & 460 \\
\hline Tungsten Carbide & 1000 \\
\hline Stainless Steel & 250 \\
\hline
\end{tabular}

The VH of the tungsten carbide coating is the highest at $1000 \mathrm{VH}$, whereas the hard chrome and chrome oxide coatings have a $\mathrm{VH}$ approximately half of that, at $450 \mathrm{VH}$. Lastly, the stainless steel sleeve has a $\mathrm{VH}$ a quarter of the tungsten carbide coating, at $250 \mathrm{VH}$.

\subsection{Surface roughness}

A Zeta-20 benchtop optical profiler is used to carry out the surface roughness and topography measurements for this work. It is a fully integrated optical profiling microscope, powered by ZDot ${ }^{\mathrm{TM}}$ technology, which simultaneously collects high-resolution 3D data and a True Color infinite focus image [13].

The surface roughness parameters of the sleeves are shown in table 3. All sleeves were manufactured for the purpose of this test. The tungsten carbide, chrome oxide and hard chrome sleeves were surface coated and treated to the desired roughness parameters. The stainless steel sleeve was left uncoated and did not have a specific surface roughness, representing a standard stainless steel shaft.

Table 3: Sleeve Surface Roughness (units: $\mu \mathrm{m}$ )

\begin{tabular}{|l|l|l|l|}
\hline & $\boldsymbol{R}_{\boldsymbol{a}}$ & $\boldsymbol{R}_{\boldsymbol{p}}$ & $\boldsymbol{R}_{\boldsymbol{v}}$ \\
\hline Hard chrome & 0.174 & 1.115 & 0.585 \\
\hline Chrome Oxide & 0.135 & 1.699 & 1.115 \\
\hline Tungsten C. & 0.187 & 0.471 & 0.689 \\
\hline Stainless Steel & 3.143 & 4.145 & 2.178 \\
\hline
\end{tabular}

The $R a$ of the hard chrome, chrome oxide and tungsten carbide sleeves fall within the desired surface roughness parameters $R a$ $=0.1-0.2 \mu \mathrm{m}$. The stainless steel sleeve has a 'rougher' surface that has not undergone any specific surface treatment or coating.

\subsection{Rotational Speeds}

Shaft speeds of 360 to 6000 RPM are tested to replicate similar conditions that the seals undergo in industry (table 4).

Table 4: Testing Speeds from 360 to $6000 \mathrm{rpm}$

\begin{tabular}{|l|l|l|}
\hline Frequency (Hz) & Input shaft & Output shaft \\
\hline 2 & 120 & 360 \\
\hline 3 & 180 & 540 \\
\hline 5.5 & 330 & 990 \\
\hline 7 & 420 & 1260 \\
\hline 10 & 600 & 1800 \\
\hline 15 & 900 & 2700 \\
\hline 20 & 1200 & 3600 \\
\hline 25 & 1500 & 4500 \\
\hline 30 & 1800 & 5400 \\
\hline 33.3 & 1998 & 6000 \\
\hline
\end{tabular}

A standardized test procedure is used for uniformity amongst all tests. Each seal-sleeve combination runs for a total of 4 hours. Each rotational speed is run for a duration of 20 minutes until all the speeds have been tested (total of 3 hours and 20 minutes). Lastly, the test is left to run at 4500 RPM for the remaining 40 minutes, completing 4 hours of testing.

\section{Results and Discussion}




\subsection{Performance of the seal-sleeve combination}

Results for leakage of seal-sleeve combinations are presented in table 5. Between the 3 spring loads, the $12.5 \mathrm{oz}$ seal (standard issue seal) had the best performance for the hard chrome, chrome oxide and tungsten carbide sleeves. There is no leakage recorded for the chrome oxide and tungsten carbide sleeves with this seal.

Overall, the $14 \mathrm{oz}$ seal leaked more than the $12.5 \mathrm{oz}$ and the $8.5 \mathrm{oz}$, having the least favourable performance between the 3 . Leakage was recorded for all sleeves tested with this seal. The $12.5 \mathrm{oz}$ seal performed second best and had no recorded leakage with the tungsten carbide sleeve.

The tungsten carbide sleeve performed the best from all 4, with no recorded leakage for the $8.5 \mathrm{oz}$ and $12.5 \mathrm{oz}$ seals and less than $1 \mathrm{ml} / \mathrm{hr}$ for the $14 \mathrm{oz}$ seal. Chrome oxide was second in performance with no recorded leakage for the $12.5 \mathrm{oz}$ seal and less than $1 \mathrm{ml} / \mathrm{hr}$ for the $8.5 \mathrm{oz}$ and $14 \mathrm{oz}$ seal. Hard chrome was third in performance, having no configurations with no recorded leakage. However, all cases had less than $1 \mathrm{ml} / \mathrm{hr}$ of recorded leakage which is still within the acceptable limits. Lastly, the stainless steel sleeve case has recorded leakage between 1-1.5 $\mathrm{ml} / \mathrm{hr}$. This is the worst performing sleeve.

A comparison between the coated (hard chrome, chrome oxide and tungsten carbide) sleeves and uncoated (stainless steel) sleeves shows that the coated sleeves collectively had lower leakage and better performance over the uncoated sleeve. The significance of the coating is in its Vickers hardness and surface roughness. Surface treating the sleeve with the desired coating alters the hardness of the sleeve and allows the surface to be machined to the desired roughness as well.

$1 \mathrm{ml} / \mathrm{hr}$ is the acceptable rate of leakage for seals.

Table 5: Total Leakage per hour (units: $\mathrm{ml} / \mathrm{hr}$ )

\begin{tabular}{|l|c|c|c|}
\hline \multicolumn{4}{|c|}{ Leakage Rate } \\
\hline & $8.5 \mathrm{oz}$ & $12.5 \mathrm{oz}$ & $14 \mathrm{oz}$ \\
\hline Hard chrome & 0.20 & 0.60 & 0.40 \\
\hline Chrome Oxide & 0.78 & 0 & 0.87 \\
\hline Tungsten Carbide & 0 & 0 & 0.50 \\
\hline Stainless Steel & 1.05 & 1.5 & 0.925 \\
\hline
\end{tabular}

During each $4 \mathrm{hr}$ test, the speed at which leakage began is recorded in table 7 . In all cases, any leakage, if present occurs after 1800 RPM. Prior to this speed, there was no leakage seen in any of the tests. This indicates leakage does not occur prior to 1800 RPM at lower speeds.

Further, from table 7 it is clear that leakage begins at the lowest recorded speed for the stainless steel sleeve. Earlier onset of leakage indicates a higher total amount of leakage recorded overtime. This is also another indicator of the low performance of this sleeve.

Table 6: Speed at which leakage begins (units: rpm)

\begin{tabular}{|c|c|}
\hline \multicolumn{2}{|c|}{ Hard chrome } \\
\hline $8.5 \mathrm{oz}$ & 2700 \\
\hline $12.5 \mathrm{oz}$ & 4500 \\
\hline $14 \mathrm{oz}$ & 4500 \\
\hline \multicolumn{2}{|c|}{ Chrome Oxide } \\
\hline $8.5 \mathrm{oz}$ & 1800 \\
\hline $12.5 \mathrm{oz}$ & - \\
\hline $14 \mathrm{oz}$ & 4500 \\
\hline \multicolumn{2}{|c|}{ Tungsten Carbide } \\
\hline $8.50 \mathrm{oz}$ & - \\
\hline $12.5 \mathrm{oz}$ & - \\
\hline $14 \mathrm{oz}$ & 2700 \\
\hline \multicolumn{2}{|c|}{ Stainless Steel } \\
\hline $8.5 \mathrm{oz}$ & 1800 \\
\hline $12.5 \mathrm{oz}$ & 1800 \\
\hline $14 \mathrm{oz}$ & 1800 \\
\hline
\end{tabular}




\subsection{Integrity of the sleeves}

The coating of the sleeve is critical in ensuring seal performance. Due to the nature of the filled PTFE, these seals can be more abrasive than standard elastomer seals. They contain glass fibres and other fillers that improve their mechanical properties considerably, reducing wear that would occur if pure PTFE were used [14].

The sleeves require a hard enough surface that will withstand the PTFE seal running on it. Most standard stainless steel shafts (series 200 and 300) would have a very low Vickers hardness of 200-300 HV or less [15] which is not ideal for the seal. A specific surface roughness is also imperative for the shaft, $R a=0.1-0.2 \mu \mathrm{m}$. This is because a slightly semi rough surface aids in additional sealing mechanisms and a perfectly smooth or extremely rough shaft would not provide this [16].

The hardness of the tungsten carbide sleeve ranges between 800-1200 HV, the highest of all four sleeves. The chrome oxide coating has a $450 \mathrm{HV}$. Further, between the chrome oxide and tungsten carbide sleeves, the chrome oxide is left with a very prominent dark seal track on the running surface of the sleeve (Fig. 5a). On the other hand, the tungsten carbide sleeve did not have any such mark and remained intact (Fig. 5b). It was the best performing coating that maintained its integrity from the four sleeves tested.
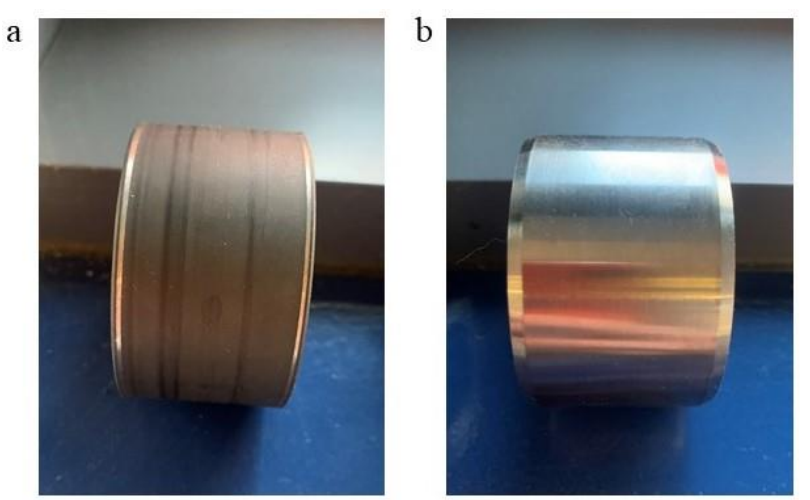

Figure 5: (a) Chrome Oxide Sleeve with visible wear track and dark area indicating material transfer where seal is mounted. (b) Tungsten Carbide Sleeve with no visible wear track where seal is mounted.

\section{Conclusions}

The leakage and performance of various seal-sleeve combinations are tested in a rotating test rig simulating a helicopter gearbox. To investigate the speed at which leakage begins and the amount of leakage in each case, a range of rotational speeds are tested. Three seals with pre-loaded garter springs loads of $8.5 \mathrm{oz}, 12.5 \mathrm{oz}$ and $14 \mathrm{oz}$ are used. Four sleeve coatings are tested here: hard chrome, chrome oxide, tungsten carbide and stainless steel. Surface profile and hardness measurements of the sleeves are taken prior to the test to ensure they are within the desired ranges. Several conclusions are drawn based on the experiment.

a) The $12.5 \mathrm{oz}$ seal (standard issue seal) had the best performance for the hard chrome, chrome oxide and tungsten carbide sleeves. There is no leakage recorded for the chrome oxide and tungsten carbide sleeves with this seal. This indicates that the $12.5 \mathrm{oz}$ seal has an optimized lip pressure for a general application, neither causing excessive wear nor excessive leakage.

b) The $14 \mathrm{oz}$ seal leaked more than the $12.5 \mathrm{oz}$ and the $8.5 \mathrm{oz}$, having the least favourable performance between the 3 seals. Leakage is recorded for all sleeves tested with this seal. A higher spring load results in more friction and wear and therefore, higher leakage rates as well.

c) The three specimens with coatings had better performance than the plain sleeve. Using hard, wear-resistant coatings helps improve the overall performance of the seal. They reduce leakage by preventing pre-mature wear of the seal and quality of the surface finish. With a plain stainless steel shaft, the onset of leakage is at lower speeds and results in overall higher leakage rates. This incurs maintenance costs due to early failure of components.

d) The tungsten carbide sleeve, with a VH of 1000 outperformed the remaining 3 sleeves. It maintained its integrity after the test and remained without a wear track. The chrome oxide sleeve performed second best. However, the sleeve did not maintain its integrity and is left with a black ring on its running surface where the seal was mounted.

e) There is no recorded leakage in any case below $1800 \mathrm{rpm}$. This indicates that leakage generally does not occur at lower speeds, even with poor seal-sleeve combinations. Higher speeds result in harsher environmental conditions of high temperature, friction and pressure, causing leakage in some cases. 
Further work on the sleeves is being done to study why the tungsten carbide sleeve coating has maintained its integrity after testing, but the chrome oxide one has not. The coatings are applied using different techniques, resulting in varying surface topographies and properties. This will play a critical role in determining how it will interact with the seal, ultimately impacting the overall performance of the seal.

\section{Acknowledgements}

This work is funded by the INNOVATIVE doctoral programme. The INNOVATIVE programme is partially funded by the Marie Curie Initial Training Networks (ITN) action (project number 665468) and partially by the Institute for Aerospace Technology (IAT) at the University of Nottingham. We would also like to thank Leonardo MW Ltd for supporting this work through a joint collaboration with University of Nottingham.

\section{References}

[1] D. Shen, "Deterministic Modeling of a Rotary Lip Seal with Microasperities on the Shaft Surface," no. December, p. $158,2005$.

[2] M. Yildiz, "Modeling and Simulation of Oil Leakage in Radial Lip Seals,” no. April, 2010.

[3] P. Baart, Grease Lubrication in Radial Lip Seals. 2009.

[4] Green Tweed and Co, "Surface Finish Guidelines,” Datasheet, 2007.

[5] R. F. Salant and A. H. Rocke, "Hydrodynamic Analysis of the Flow in a Rotary Lip Seal Using Flow Factors," J. Tribol., vol. 126, no. 1, p. 156, 2004.

[6] B. E. T. Jagger, B. S. Eng, and P. D. Associate, "ROTARY SHAFT SEALS : THE SEALING MECHANISM OF SYNTHETIC RUBBER SEALS RUNNING AT ATMOSPHERIC PRESSURE,” no. June, 1956.

[7] A. Gabelli, "Formation of Lubricant Film in Rotary Sealing Contacts : Part II — A New Measuring Principle for Lubricant Film Thickness," no. 90, 1992.

[8] H. Van Leeuwen and M. Wolfert, "The sealing and lubrication principles of plain radial lip seals : an experimental study of local tangential deformations and film thickness," 1997.

[9] L. Horve, “The Effect of Operating Parameters Upon Radial Lip Seal Performance,” 2018.

[10] “The Importance of Seal Running Surface | Tritec Seal | TRITEC Performance Solutions.” [Online]. Available: https://www.tritec-ps.com/the-importance-of-seal-running-surface/. [Accessed: 04-Feb-2020].

[11] K. Legg et al., "Hard Chromium Alternatives Team Update - Improving Performance While Reducing Cost The Hard Chrome Alternatives Team ( HCAT ) is a joint effort by the defense performance and acceptable cost, it has been found that performance is usually For more informa."

[12] O. H. C. Standard, “Aeroshell 555 Material Safety Data Sheet.” pp. 1-5, 2008.

[13] “Zeta-20 Optical Profiler | Surface Profilers | KLA.” [Online]. Available: https://www.klatencor.com/products/surface-profilers/zeta-20-optical-profiler. [Accessed: 12-Feb-2020].

[14] C. Paper, "A review of the tribological properties of PTFE composites filled with glass, graphite , carbon or bronze reinforcement A REVIEW OF THE TRIBOLOGICAL PROPERTIES OF PTFE COMPOSITES FILLED WITH GLASS , GRAPHITE , CARBON OR,” no. January, pp. 135-140, 2017.

[15] SSINA AISI, “Design Guidelines for Selection and Use of Stainless Steels (9014),” Nickel Dev. Inst., p. $54,2011$.

[16] "Improving Component Life In The Aerospace Sector - Coatings World.” [Online]. Available: https://www.coatingsworld.com/issues/2016-05-01/view_features/improving-component-life-in-the-aerospace-sector/. [Accessed: 19-Feb-2020]. 